\title{
Levantamento das espécies de Simulium (Diptera, Simuliidae), Riacho dos Padres, município de Almirante Tamandaré, Paraná, Brasil
}

\author{
Ana Leuch Lozovei ${ }^{1}$, Fabiane Petry $^{1}$, Luiz Gonzaga dos Santos Neto ${ }^{1}$ \& Maria Elizabeth Ferraz ${ }^{2}$
}

'Departamento de Patologia Básica, Setor de Ciências Biológicas, Universidade Federal do Paraná. Caixa Postal 19031, 81531-990

Curitiba-PR, Brasil. Endereço eletrônico: alozovei@terra.com.br

${ }^{2}$ Centro de Saúde Ambiental, Torre A, Prefeitura Municipal de Curitiba. Av. João Gualberto 623, 80030-000 Curitiba-PR, Brasil.

\begin{abstract}
Survey of the Simulium species (Diptera, Simuliidae), Riacho dos Padres, Almirante Tamandaré municipality, Paraná, Brazil. From January to August 2002, collections of simuliid larvae, both in natural and anthropic substrates, were carried out biweekly in Riacho dos Padres. This study provides a local inventory of species and their relative frequencies. The area is a private property located in the Curitiba metropolitan area, and it is dedicated mainly to farming fish, rabbits, sheep, cattle, poultry and also featuring recreational activities for visitors such as horse back riding. The constant presence of vertebrate hosts and food given to the fish provided a constant supply of food resources, thus leading to a local explosion of this insect nuisance. A total of 24,021 pupae and 197,812 larvae were collected on all kinds of substrate. From the pupae, the following species and respective frequencies were identified: Simulium inaequale (55.24\%), Simulium perflavum (16.81\%), Simulium pertinax (13.93\%), Simulium orbitale $(8.03 \%)$, Simulium subnigrum $(4.92 \%)$, Simulium distinctum $(1.03 \%)$ and Simulium incrustatum $(0.04 \%)$. The total number of larvae colonizing all substrates was also computed.
\end{abstract}

Keywords. Breeding ground; Simulium; species frequency; stream.

Resumo. De janeiro a agosto de 2002, quinzenalmente, foi levada a efeito a coleta de simulídeos imaturos em substratos naturais e antrópicos no Riacho dos Padres. O trabalho visou proceder ao inventário das espécies e verificar as freqüências relativas. A área de propriedade particular localizada na Região Metropolitana de Curitiba constitui uma microempresa de agronegócio, com criação de peixes, coelhos, ovinos, bovinos, aves domésticas e, ainda, área de lazer com eqüinos para cavalgada de visitantes. A presença constante de animais hospedeiros e a ração fornecida aos peixes garantiram farta alimentação aos simulídeos, o que favoreceu a explosão desta praga. Em todos os substratos foram coletadas 24.021 pupas e um total de 197.812 larvas. A partir de pupas, foram identificadas com as seguintes frequiências: Simulium inaequale (55,24\%), Simulium perflavum (16,81\%), Simulium pertinax $(13,93 \%)$, Simulium orbitale $(8,03 \%)$, Simulium subnigrum (4,92\%), Simulium distinctum (1,03\%) e Simulium incrustatum $(0,04 \%)$. Verificou-se também a quantidade de larvas que colonizaram todos os substratos.

Palavras-Chave. Criadouro; freqüência de espécies; riacho; Simuliidae; vertedouros.

Os simulídeos distribuem-se em todas as regiões zoogeográficas e englobam 1.787 espécies válidas até o início de 2002 (CROSSKEY 2002). As espécies hematófagas constituem uma praga incômoda e molestante, tanto para humanos como para animais domésticos. As espécies que picam humanos fazem parte de quatro gêneros: Simulium Latreille, 1802, Prosimulium Roubaud, 1906, Austrosimulium Tonnoir, 1925 e Cnephia Enderlein, 1921. Muitas espécies de Simulium são de interesse médico-veterinário por veicularem diferentes organismos patogênicos aos homens e animais (SERVICE 1997; Crosskey 1993). Por essa razão, espécies desse gênero têm suscitado investigações de ordem bionômica, ecológica, taxonômica e sobre métodos de controle químico e bacteriológico e técnicas de manejo mecânico.

Nas regiões Afrotropical e Neotropical, várias espécies de Simulium veiculam aos humanos a filária Onchocerca volvulus (Leuckart, 1893). A oncocercose constitui um sério problema de saúde pública por determinar cegueira irreversível em indivíduos oncocercóticos. Ocorre na África Tropical, ao sul do Saara e no Continente Americano, mormente em países localizados entre as linhas do Equador e o Trópico de Câncer.
No Brasil, sua ocorrência foi registrada na Amazônia, em focos isolados, e no norte de Goiás (FERreira \& Rocha 1991).

A oncocercose em áreas endêmicas também se torna um fator negativo do desenvolvimento econômico em extensas regiões férteis. Nos Estados Unidos da América, algumas espécies de simulídeos transmitem helmintos, como a Dirofilaria Railliet \& Henry, 1911, que parasita os ursos, Leucocytozoon smithi (Leveran \& Lucet, 1905), que parasita o sangue de galináceos (perus) e Leucocytozoon simondi (Mathis \& Leger, 1910), que parasita o sangue de patos domésticos. Também aos simulídeos atribui-se a transmissão mecânica de vírus da mixomatose aos coelhos. Na Venezuela, suspeita-se do envolvimento de algumas espécies na veiculação de vírus da encefalite eqüina (VEE) (CROSSKEY 1993).

Em algumas localidades do mundo, os simulídeos proliferam tão descontroladamente que chegam a deteriorar profundamente a qualidade de vida da população, atuando como vetores de organismos patogênicos e como pragas hematófagas de seres humanos e animais domésticos. Suas picadas podem provocar reações alérgicas que requerem assistência médica. Em muitas áreas, os simulídeos 
hematófagos ora impedem o desenvolvimento turístico, ora determinam impactos econômicos negativos nas fazendas, em que, debilitando ou importunando o gado, reduzem a produtividade ou impedem a execução do trabalho no campo ou até interferem no aprendizado de crianças em escolas (STRIEDER et al.1992; SERVICE 1997).

A Chácara Evíssima no Riacho dos Padres, que sofreu profunda modificação antrópica, foi o local em que se realizou o presente estudo. A constante presença de simulídeos chegou a atrapalhar a execução dos trabalhos na lavoura. A população massiva e constante destes insetos provocou um impacto não só na Chácara Evíssima, mas influiu também diretamente sobre o bem-estar e qualidade de vida de toda a comunidade.

A presente investigação propôs-se: a) identificar as espécies de Simuliidae no segmento do Riacho dos Padres com leito modificado, sua distribuição e frequiência; b) conferir a freqüência larvária em substratos naturais e antrópicosfitilhos de três cores e c) procurar in loco quais os fatores que explicassem, pelo menos em parte, a excessiva proliferação destes insetos nesta área.

\section{MATERIALE MÉTODOS}

O trabalho foi executado no município de Almirante Tamandaré, região metropolitana de Curitiba, situado cerca de $17 \mathrm{~km}$ ao norte da Capital.

O Riacho dos Padres, afluente do Rio Tanguá, integra a Bacia do Rio Barigüi e percorre, no sentido norte-sul, os municípios de Almirante Tamandaré, Curitiba e Araucária (MAACK 1981). Das nascentes até desembocar no Rio Iguaçu, conta com uma extensão aproximada de $60 \mathrm{~km}$. De 260,10 km² de área total drenada, $94,75 \mathrm{~km}^{2}$ pertencem ao município em estudo.

O clima desta bacia caracteriza-se como subtropical úmido mesotérmico, com verões frescos e ocorrência de geadas severas e freqüentes no inverno, sem estação seca. As precipitações pluviométricas permanecem regulares todos os meses do ano. A média de temperaturas nos meses mais quentes é inferior a $22^{\circ} \mathrm{C}$ e, nos mais frios, inferior a $18^{\circ} \mathrm{C}$ (FERREIRA 1996).

O relevo desta área apresenta uma paisagem suavemente ondulada com formação Guabirotuba ou um relevo abrupto com predominância de rochas Pré-Cambrianas e as altitudes situam-se em torno de $900 \mathrm{~m}$ (SUREHMA 1986). Os principais tipos de solos na bacia são o Latossol Vermelho Amarelo Álico Câmbrico com proeminente textura argilosa.

A Chácara Evíssima localiza-se cerca de $1 \mathrm{~km}$ à jusante da nascente do Riacho dos Padres. Na propriedade, desenvolvese um pequeno agronegócio com criação de peixes, coelhos, ovinos, bovinos e de aves domésticas, além de animais eqüinos mantidos para o lazer de visitantes (cavalgadas).

A pesquisa de simulídeos teve início por solicitação do proprietário, com o objetivo de reduzir esta praga hematófaga mediante controle dos insetos a fim de viabilizar o empreendimento de eventos e de turismo rural.

Com sua nascente numa propriedade contígua, o Riacho dos Padres, de leito modificado com cinco tanques de piscicultura, atravessa a Chácara Evíssima numa extensão de aproximadamente $330 \mathrm{~m}$ para entrar na propriedade seguinte. Em um segmento de $200 \mathrm{~m}$ do leito modificado foi desenvolvida a presente pesquisa. Para a saída da água, cada tanque possui um vertedouro (conhecido como ladrão ou escoadouro), normalmente de cimento ou de pedras irregulares em desnível expressivamente acentuado. Além da laje dos vertedouros, serviram de substrato a vegetação aquática, a de beira do riacho parcialmente submersa, e os substratos artificiais, os fitilhos, introduzidos neste habitat. Nestes tipos de substratos é que foram efetuadas as coletas de imaturos de simulídeos.

O estudo foi iniciado em dezembro de 2001 para inventariar as espécies. As amostras coletadas serviram de levantamento faunístico preliminar de substratos naturais e antrópicos para adequar a metodologia.

O estudo definitivo foi realizado de janeiro a julho de 2002, num total de 12 amostragens quinzenais. Os substratos artificiais introduzidos no biótopo, nas cores azul, branca e amarela, consistiram no total de 180 fragmentos de fitilhos de polietileno (65\%) com polipropileno (35\%), em dimensões de $150 \mathrm{~cm}$ de comprimento por $0,5 \mathrm{~cm}$ de largura, presos a um suporte transversal de margem a margem num segmento do leito do riacho, entre dois tanques. Também foram armados fitilhos de iguais dimensões na laje de 10,48 $\mathrm{m}$ de comprimento por 1,07 $\mathrm{m}$ de largura no vertedouro do último tanque. Para coletar imaturos nestes substratos, removiam-se de cada vez todos os fitilhos (cinco de cada cor) e deixavam-se outros iguais e nos mesmos lugares.

A amostragem nos substratos naturais variou de acordo com o tipo de substrato. Em vegetais aquáticos ou semiaquáticos, os imaturos eram removidos junto com os vegetais colonizados. Quando em pedras ou em cimento, procedia-se à raspagem. Nenhum tipo de substrato de simulídeos imaturos foi preterido para conseguir dados completos sobre a frequiência das espécies. As amostras de imaturos coligidas, acondicionadas em recipientes de polietileno e em caixa de poliestireno com gelo e transportadas ao laboratório, foram triadas, selecionadas e computadas.

CunHa (2001) considerou larvas do primeiro estádio as que tinham ovi ruptor na parte dorsal da cabeça e antenas de um artículo; as do segundo, de dois artículos e as do terceiro em diante, de três artículos. Na investigação do Riacho dos Padres, as larvas foram separadas em três classes: consideraram-se de $1^{\text {a }}$ classe, as de comprimento entre 0,5 a $1,0 \mathrm{~mm}$, com ovi ruptor e antenas de um só artículo; de $2^{\mathrm{a}}$ classe, as que apresentassem entre 1,2 e 2,0 $\mathrm{mm}$ e antenas de dois artículos; de terceira classe, as que tivessem comprimentos superiores aos supra referidos, porém, munidas de antenas de três artículos, com esboço de histoblasto e as de histoblasto plenamente formado.

Os principais substratos vegetais das margens e do leito do riacho, que serviram de suporte para fixação de imaturos, foram: Cyperus sp. (Cyperacea), Eleocharis nodulosa (Roth) Schult (Cyperaceae), Paspalum sp. (Poaceae) e Zantedeschia aethipica Sprengler (Araceae).

A identificação das espécies baseou-se em características morfológicas de pupas, montadas entre lâminas e lamínulas, 
utilizando-se chaves dicotômicas indicadas em CoscARón \& WygODZINSKY (1984), CosCARÓN (1991) e STRIEDER et al. (1992).

Em caso de dúvida quanto à identificação, os exemplares adultos serviram de suporte para dirimi-la. A obtenção de adultos em laboratório a partir de pupas baseou-se em técnica de Vulcano (1962). Na montagem de adultos, seguiu-se o método indicado em COSCARÓN (1981).

\section{RESULTADOSEDISCUSSÃO}

Foram coletados 24.021 exemplares de pupas, que serviram de base para a identificação das espécies. Em ordem decrescente, as espécies acusaram variadas freqüências: Simulium (Inaequalium) inaequale Peterson \& Shannon, 1927 (55,24\%), S. (Ectemnaspis) perflavum Rouband, 1906 (16,81\%), S. (Chirostilbia) pertinax Kollar, 1932 (13,93\%), S. (Thyrsopelma) orbitale Lutz, 1910 (8,03\%), S. (Inaequalium) subnigrum Lutz, 1910 (4,92\%), S. (Chirostilbia) distinctum Lutz, 1910 (1,03\%) e S. (Psaroniocompsa) incrustatum Lutz, $1910(0,04 \%)$.

No Riacho dos Padres, no segmento amostrado, a freqüência das sete espécies coletadas não foi homogênea nem em substratos naturais nem em antrópicos. Considerando a ocorrência em todos os substratos, algumas espécies parecem mais adaptadas às condições ambientais do biótopo. De um modo geral, a dinâmica populacional de $S$. inaequale demonstrou o melhor desempenho e equilíbrio no habitat em todos os tipos de substratos, somando 13.270 pupas. Esta espécie sobressaiu pela maior frequiência durante o período investigado provavelmente porque conseguiu adaptar-se melhor às condições ambientais e hidrológicas, onde a água enriquecida com nutrientes da ração de peixes propiciou-lhe um habitat adequado à procriação.

Seguindo o mesmo raciocínio, a segunda espécie mais ocorrente no habitat estudado foi $S$. perflavum com 4.037 exemplares, também presente em todos os tipos de substratos. Com 3.346 exemplares, $S$. pertinax igualmente não faltou em nenhum dos suportes. As três espécies destacaram-se pelas melhores freqüências no riacho, somando juntas um total de $85,98 \%$ de espécimes. As três seguintes ocorreram em todos os substratos, porém em menor quantidade: $S$. orbitale com 1.930 exemplares, S. subnigrum com 1.182 e S. distinctum com 247. Por último, $S$. incrustatum com somente 9 , a única de freqüência esporádica, com poucos representantes e ausente em alguns substratos.

Considerando a frequiência sob o ponto de vista de substratos-fitilhos, o comportamento também foi bastante diversificado. Do total de 17.426 pupas, $S$. inaequale superou as demais espécies, atingindo $51,81 \%$ do total $(\mathrm{n}=9.028)$. Em segundo lugar, $S$. perflavum fez-se presente com certa constância com $18,20 \%$ (3.171) e S. pertinax com $15,52 \%$ (2.705). Seguiram depois, S. orbitale com 9,36\% (1.632), $S$. subnigrum com 3,75\% (654), S. distinctum com 1,34\% (234) e, por último, $S$. incrustatum com $0,02 \%$ (2), ocorrendo esporadicamente.

Comparando a ocorrência das espécies em substratos vegetais, do total de 4.836 pupas, $S$. inaequale novamente foi a mais freqüente, $66,29 \%(\mathrm{n}=3.206)$, seguida de $12,83 \%$ (620) de S. perflavum, 10,07\% (487) de S. subnigrum, 7,53\% (364) de $S$. pertinax e 3,12\% (151) de $S$. orbitale. Por último, ficaram $S$. incrustatum com $0,14 \%$ (7) e $S$. distinctum com $0,02(1)$.

Em substratos de pedras e cimento, do total de 1.759 pupas, $S$. inaequale foi também a espécie mais freqüente com $58,90 \%$ (n = 1.036). Seguiram-na $S$. pertinax com $15,75 \%$ (277), $S$. perflavum com $13,98 \%$ (246), S. orbitale com 8,36\% (147), $S$. subnigrum com 2,33\% (41) e $S$. distinctum com $0,68 \%$ (12). Não foram encontrados exemplares de $S$. incrustatum. Nestes substratos, comparados aos outros utilizados, as espécies destacaram-se pela menor abundância.

O número de larvas superou em muito o de pupas em todos os substratos, em que foram coligidas amostras no Riacho dos Padres; as larvas alcançaram um total de $89,17 \%$ ( $\mathrm{n}=$ 197.812) e as pupas, somente $10,83 \%(n=24.021)$.

Considerando o resultado de larvas, no leito do riacho constatou-se um número maior de larvas nas duas primeiras classes de tamanho, 60,44\% $(n=119.559)$ que os de terceira classe, 39,56\% (78.253). Com respeito à colonização em lajes de um dos vertedouros, aconteceu o inverso, houve maior número de larvas da terceira classe, com 71,01\% (109.038) que os $28,99 \%$ (44.520) da primeira e segunda classes de tamanho. Embora as amostras tenham sido coligidas em datas equiidistantes em todos os substratos, convém ressaltar, no entanto, que, em vertedouros, houve predomínio de larvas de terceira classe de tamanho. Isto deve ser relacionado com a elevação do teor de oxigênio dissolvido e com a renovação constante de partículas alimentares.

Ao comparar a freqüência de larvas entre diversos tipos de substratos, os fitilhos foram colonizados mais intensamente que os vegetais, pedras e cimento juntos. Na verdade, na área houve maior número de fitilhos que de outros suportes, excetuando-se os vertedouros. As três cores de fitilhos (azul, branco e amarelo) somadas alcançaram o percentual de $87,38 \%$ $(\mathrm{n}=172.855)$ de larvas contra $12,62 \%(\mathrm{n}=24.957)$ em vegetais, pedras e cimento juntos. Ao individualizar as cores, os fitilhos brancos contribuíram com $25,16 \%(n=49.765)$, os azuis com $28,44 \%(n=56.259)$ e os amarelos foram os mais colonizados, $33,78 \%(n=66.831)$. Em contraposição, a ocorrência de larvas em vegetais foi de apenas $8,57 \%(\mathrm{n}=16.947)$ e, em pedras, cimento e blocos soltos no leito, menor ainda, $4,05 \% \quad(\mathrm{n}=$ 8.010).

Dellome Filho (1992) utilizou duas cores de fitilhos como substrato; a representatividade populacional de imaturos de Simuliidae prevaleceu em fitilhos amarelos com 76,79\%, mais que os 23,21\% em verdes. Maior número de imaturos em fitilhos amarelos ao lado de brancos também constataram ELSEN \& HERBRARD (1977). No presente trabalho, a colonização predominante em fitilhos amarelos foi a mais expressiva como nas duas pesquisas referidas.

Araúso-Coutinho et al. (1998), em pesquisa no estado de São Paulo, nos municípios litorâneos de Caraguatatuba, Ilhabela, São Sebastião e Ubatuba, área turística, abordaram a infestação de simulídeos em 358 criadouros de 108 localidades. De 1.577 exemplares de pupas identificaram 14 espécies. Do 
total dos exemplares coletados, a maior representatividade coube a $S$. pertinax com $92 \%$ de frequiência, seguida de $S$. incrustatum com 40\%. Na área da Chácara Evíssima, no Riacho dos Padres, os resultados confirmam que as características ecológicas do criadouro favoreceram a proliferação com maior representatividade das espécies de S. inaequale, S. perflavum e $S$. pertinax.

Em Morretes, na planície litorânea do Paraná, os trabalhos desenvolvidos por Dellome Filho (1991) no Rio Marumbi e CunHA \& BASsI (1997) no Rio São João, constataram a presença de doze espécies de simulídeos: Lutzsimulium hirticosta (Lutz 1909), Simulium pertinax, S. lewisi Ramírez-Perez, 1971, S. subnigrum, S. orbitale, S. inaequale, S. riograndense PyDaniel, Souza \& Caldas, 1988, S. acarayense Coscarón \& Wygodzinsky, 1972, S. perflavum, S. romanai Wygodzinsky, 1951, S. subclavibranchium Lutz, 1910, e S. incrustatum. A última espécie da lista ocorreu com maior frequiência em ambas as pesquisas $85,80 \%$ e $65,10 \%$, respectivamente. No presente trabalho, porém, atingiu somente $0,04 \%$ de freqüência.

Dentre as doze espécies acima citadas, embora em percentuais de freqüência alterados, seis coincidiram com as coletadas nesta pesquisa, não obstante as diferenças de altitude e de clima entre o litoral e o planalto, local destes trabalhos.

No Primeiro Planalto Paranaense, Lozover et al. (1989) no Rio Dom Rodrigo e Cunha et al. (1998) no Rio Cachoeirinha, no município de Campo Largo, constataram a ocorrência de sete espécies: $S$. acarayense, $S$. incrustatum, $S$. inaequale, S. orbitale, S. pertinax, S. auripellitum Enderlein, 1933, S. subpallidum Lutz, 1910. As cinco primeiras espécies ocorreram no Rio Cachoeirinha, e as outras duas e mais três coincidentes, no Rio Dom Rodrigo. Da relação, somente S. inaequale, $S$. orbitale e $S$. pertinax participaram de ambos os habitats. De todas, sobressaíram com maior representatividade populacional S. subpallidum $(74,12 \%)$ no Rio Dom Rodrigo, S. acarayense $(26,18 \%)$ no Rio Cachoeirinha e $S$. inaequale $(55,24 \%)$ no Riacho dos Padres.

As pesquisas do Rio Marumbi (Dellome Filho 1991) e as do Rio São João (CunHA \& BASSI 1997), ambas em altitude e clima semelhantes da área litorânea, apresentaram resultado coincidente em 33\% de espécies registradas. No Primeiro Planalto Paranaense, nas pesquisas do Rio Cachoeirinha (CunHa et al. 1998) e no Rio Dom Rodrigo (Lozovel et al. 1989), localizados em Campo Largo, deu-se uma coincidência de espécies coletadas em 43\%. Ao comparar estas últimas duas pesquisas com a do Riacho dos Padres, todas em municípios próximos geograficamente e de clima semelhante, houve igualmente uma coincidência de $43 \%$ das espécies.

Agradecimento. À Coordenadoria de Controle de Zoonoses e Vetores da Prefeitura Municipal de Curitiba, Paraná, pelo apoio logístico que funciona junto ao Programa de Controle de Simulídeos nos arredores de Curitiba e Região Metropolitana.

\section{REFERÊNCIAS}

Araújo-coutinho, C. J. P. C.; M. Maia-herzog \& B. C. Souza. 1988. Levantamento das espécies do gênero Simulium Latreille (Diptera, Simuliidae) no Litoral Norte do Estado de São Paulo. Revista Brasileira de Entomologia 32(1): 11-17.

Coscarón, S. 1981. Fauna de agua dulce de la Republica Argentina. Simuliidae (Insecta, Diptera) vol. 38, n ${ }^{\circ}$ 1. Buenos Aires, Ed. Fundación para la Educación, la Ciencia y la Cultura (FECIC), $105 \mathrm{p}$.

Coscarón, S. 1991. Fauna de agua dulce de la República Argentina. Simuliidae (Insecta, Diptera) vol. $38 \mathrm{n}^{\circ}$ 2. Buenos Aires, Ed. Fundación para la Educación, la Ciencia y la Cultura (FECIC), $304 \mathrm{p}$.

Coscarón, S. \& P. Wygodzinsky. 1984. Notas sobre Simulidos neotropicales VII. Sobre los subgeneros Psaroniocompsa Enderlein y Inaequalium Subgen. nov. Arquivos de Zoologia 31(2): 37-103.

Crosskey, R. W. 1993. Blackflies (Simuliidae), p. 240-287. In: R. P. Lane \& R. W. Crosskey (ed.). Medical Insects and Arachnids London, Chapman \& Hall, ix+723 p.

Crosskey, R. W. 2002. Second update to the taxonomic and geographical inventory of world blackflies (Diptera, Simuliidae). London, The Natural History Museum, $14 \mathrm{p}$.

Cunha, M. C. I. DA. 2001. Simulídeos (Borrachudos), p. 31-47. In: C. B Marcondes (ed.). Entomologia Médica e Veterinária. São Paulo, Atheneu, $\mathrm{xi}+432 \mathrm{p}$

Cunha, M. C. I. DA \& R. M. A. DE BAssi. 1997. Ensayo con Bacillus thuringiensis var. israelensis sobre simúlidos (Diptera, Simuliidae) en el río São João, Paraná, Brasil. Acta Biológica Paranaense 26(1,2,3,4): 9-21.

Cunha, M. C. I. Da.; S. Coscarón \& R. M. A. DE BAssi. 1998. Determinación de los estadios larvales de Simulium (Diptera, Simuliidae) de Paraná, Brasil. Acta Biológica Paranaense 27(1,2,3,4): 57-66.

Dellome Filho, J. 1991. Simuliofauna do Rio Marumbi (Morretes, Paraná, Brasil). I. Coleta e Criação; Dados Meteorológicos e Físico-químicos do Criadouro; Adultos (Diptera, Simuliidae). Acta Biológica Paranaense 20(1,2,3,4): 145-156.

Dellome Filho, J. 1992. Simuliofauna do Rio Marumbi (Morretes, Paraná, Brasil). II. Substratos naturais e artificiais dos imaturos e fauna associada (Diptera, Simuliidae). Acta Biológica Paranaense 21(1,2,3 4): 77-88

Elsen, P. \& G. Hebrard. 1977. Sampling methods for preimarginal populations of Simulium damnosum Theobald, 1903 (Diptera, Simuliidae) in West Africa. II. Observations on the choise of colours development of the populations and horizontal distribution by means of plastic strips. Tropenmedical Parasitology 28(4): 471-477.

Ferreira, J. C. V. 1996. O Paraná e seus Municípios. Maringá, Ed. Memória Brasileira, 728 p.

Ferreira, F. S. C. \& L. A. C. Rocha. 1991. Filaríases, p. 869-886. In: R. Veronesi (ed.). Doenças Infecciosas e Parasitárias. $8^{\mathrm{a}}$ ed. Rio de Janeiro, Guanabara, 1082 p.

Lozovei, A. L.; M. C. I. da Cunha \& R. M. A. DE Bassi. 1989. Estudo das espécies de Simulídeos (Diptera, Simuliidae), que se procriam em vertedouros de açudes de piscicultura, Região Metropolitana de Curitiba, Paraná, Brasil. Anais da Sociedade Entomológica do Brasil 3: 103-111.

MAACK, R. 1981. Geografia Física do Estado do Paraná. 2a ed. Rio de Janeiro, Livraria José Olympio, 450 p.

Service, M. W. 1997. Medical Entomology. London, Chapmann \& Hill, $\mathrm{x}+267 \mathrm{p}$.

Strieder, M. N.; E. Corseuil \& V. Py-Daniel. 1992. Espécies do gênero Simulium (Diptera, Simuliidae) ocorrentes no Rio Grande do Sul, Brasil, com chaves para sua identificação. Acta Biológica Leopoldensia 14(2): 53-74.

SUREHMA-Superintendência de Recursos Hídricos e Meio Ambiente. 1986. Estudos da Bacia Hidrológica do Rio Barigüi, Curitiba, Paraná. 82 p.

Vulcano, M. A. 1962. Simulídeos da Serra de Bocaina: observações bionômicas, revalidação de Simulium brevisfurcatum Lutz e descrição de uma espécie nova Simulium ana-mariae (Diptera, Simuliidae) Papeis Avulsos do Departamento de Zoologia 15(19): 239-272.

Recebido em 18.VI.2003; aceito em 25.I.2004 